\title{
EDITORIAL
}

\section{Artículo científico: pautas para elaborar una buena introducción}

Redactar el artículo científico es como contar una historia, el inicio narrativo de esta historia es la introducción; por este motivo, el autor debe preocuparse que este inicio sea ameno y breve, pero con una adecuada información. La introducción debe proveer información suficiente para que el lector entienda:

$>$ El contexto de problema (Problema)

$>$ Trabajos previos que reportaron soluciones al problema (Antecedentes)

$>$ El vacío científico detectado (Justificación teórica)

$>$ El propósito del estudio (Objetivo).

Los dos primeros puntos se redactan con información técnico-científica y desde aspectos generales a aspectos específicos. Construir esta parte de la introducción implica: (a) detectar, obtener y consultar bibliografía útil para los propósitos del estudio, y (b) extraer y recopilar información relevante que atañe al problema de investigación, es decir, una gran proporción de información de los últimos 5 años y fuentes primarias (artículos científicos).

Producto de la información revisada, el autor debe ser capaz de detectar el vacío científico, el hueco, que espera cubrir con los resultados de su investigación. Entiéndase que el vacío científico es la razón de ser del artículo científico, es lo que los editores evalúan para aceptar o rechazar un manuscrito. El vacío científico puede ser simplemente un par de líneas de toda la introducción. Finalmente, el objetivo del estudio se redacta en la misma línea al vacío científico detectado.

Incorporar información a la introducción implica hacerlo parafraseando, es decir, redactando la literatura con propias palabras. Se debe minimizar la cita textual, para reducir las posibilidades de incurrir en plagio. En cualquiera de los casos, siempre se debe dar crédito al autor de la información original.

Algo importante que no hay que descuidar en la introducción es el control de las citas con la bibliografía, así, chequee que los autores citados al interior del texto aparezcan en la bibliografía y viceversa.

¿quiere ser leído y no aburrir en el intento?... ¡ haga una buena introducción! 